\title{
Developing alcohol SBI policy and procedures with Alaska Public Health Nursing
}

\author{
Rebecca Porter*, D King, B Hanson, S Faulkner \\ From INEBRIA 12th Congress, \\ Atlanda, GA, USA. 24-25 September 2015
}

\section{Background}

The Institute of Medicine recommends changing organizational policy as a key element of evidence-based practice (EBP) implementation; however, policy change alone may be insufficient to change provider practice behavior [1,2]. Engaging key organizational stakeholders in the policy change process may foster buy-in, particularly if the policy is piloted and refined alongside the new practice. As part of a two-year initiative funded by $\mathrm{CDC}$ to implement routine alcohol screening and brief intervention (SBI) into primary care settings, the Alaska Section of Public Health Nursing (PHN) collaborated with the University of Alaska Anchorage to pilot alcohol SBI policy and procedures in three clinics prior to systemwide dissemination.

\section{Material and methods}

Key PHN stakeholders and researchers formed a planning team to develop a draft alcohol SBI policy and nurse providers from pilot clinics were trained in the standardized procedures. Throughout the pilot, the university team maintained frequent contact with the clinics and monitored implementation through tracking data and contact notes. Findings were shared with the planning team regularly and the draft alcohol SBI policy and procedure was revised to balance fidelity to EBP with feasibility for PHN.

\section{Results}

Screening rates, one measure of implementation success, increased throughout the pilot as barriers and challenges were identified and addressed, with corresponding updates to organizational policy and procedure. Nurses also indicated increased confidence and ability to conduct SBI as outlined in the policy. After fourteen revisions, the universal alcohol SBI policy and procedure was finalized and disseminated throughout Alaska's PHN system. Together, findings reveal that piloting and revising draft policy was an important implementation facilitator.

\section{Conclusions}

Piloting and refining an organizational policy and procedure for alcohol SBI was effective for feasibility purposes and to implement the EBP with fidelity. Including nurses, leadership, and researchers throughout the implementation process fostered engagement in practice change.

\section{Acknowledgements}

The authors would like to acknowledge Alaska Public Health Nurses who volunteered to participate the pilot project to implement the routine practice of alcohol SBI.

\section{Published: 24 September 2015}

\section{References}

1. Institute of Medicine, Committee on Quality of Health Care in America: Crossing the quality chasm: A new health system for the 21st century Washington DC: National Academy Press; 2001.

2. Institute of Medicine: Knowing what works in health care: A roadmap for the nation Washington, DC: National Academy Press; 2008.

doi:10.1186/1940-0640-10-S2-032

Cite this article as: Porter et al.: Developing alcohol SBI policy and procedures with Alaska Public Health Nursing. Addiction Science \& Clinical Practice 2015 10(Suppl 2):O32.

\footnotetext{
* Correspondence: rrporter2@uaa.alaska.edu

Center for Behavioral Health Research \& Services, University of Alaska

Anchorage, Anchorage, USA
} 